\title{
A brief motivational intervention based on positive experience and temporary smoking abstinence: Feasibility in a psychiatric hospital
}

\author{
Ineke Keizer* \\ Aurélia Bruegger* \\ Marianne Gex-Fabry* \\ Patricia Borrero** \\ Jean-Paul Humair*** \\ Patrice Croquette* \\ Nawaz Khan Aqal* \\ * University Hospitals of Geneva, \\ Department of Mental Health and Psychiatry, \\ Chêne-Bourg \\ ** University Hospitals of Geneva, \\ Nursing Directorate, Geneva \\ *** University Hospitals of Geneva, \\ Department of Community Medicine \\ and Primary Care, Geneva
}

SWITZERLAND

\begin{abstract}
Background and Objectives: Feasible interventions promoting tobacco cessation need to be implemented in psychiatric hospitals, where high proportions of patients are heavy smokers. This pilot study examined the feasibility of a new brief motivational intervention associating positive experiences with temporary smoking cessation.

Methods: One-day interventions were proposed to 19 smokers hospitalized for severe mental disorders. The multicomponent intervention comprised a 25 -hour tobacco cessation period, information about smoking, attending thermal baths and music therapy sessions, intensive group support and feedback sessions. Expired carbon monoxide was monitored and nicotine replacement was available. Patients were evaluated before, during and after the intervention.

Results: Most participants were heavy smokers $(68.4 \%)$ and precontemplative about smoking cessation (52.6\%). Rates of successful smoking abstinence were $78.9 \%$ after 10 hours and $47.4 \%$ at 25 hours; $15.8 \%$ stopped for 3 days or more. Median CO level decreased from 24 to $9 \mathrm{ppm}$. Patients reported high levels of general well-being and satisfaction during the abstinence day. Psychiatric condition did not deteriorate and frequency of withdrawal symptoms was low. $84 \%$ of patients used nicotine replacement. Significantly reduced cigarette consumption persisted for at least one week after the intervention.
\end{abstract}


Conclusions: A brief motivational intervention based on the association between positive experience and temporary smoking abstinence is feasible in a psychiatric hospital. The reported positive experience calls for further development and validation of integrative interventions, which are currently lacking.

Received: 29 November 2010

Revised: 19 July 2011

Accepted: 17 November 2011

\section{Background and objectives}

With high smoking rates, heavy tobacco use and low quit rates, psychiatric patients are particularly at risk of morbidity and premature mortality related to smoking ${ }^{1,2}$. In inpatient psychiatric settings, partial and total smoking bans are not very effective in assisting people to quit in the longer term ${ }^{3}$ and smoke-free policies alone are insufficient measures to address tobacco dependence $^{4}$. Psychiatric hospitalization is an opportunity for brief interventions aimed at changing attitudes to smoking, enhancing motivation and facilitating access to smoking cessation programs.

Several types of cessation programs have shown to be effective, for smokers with or without psychiatric disorders ${ }^{5-7}$. Tobacco addiction is a chronic disorder ${ }^{8}$ and treatment implies multiple quit attempts and relapses, with single interventions showing low success rates ${ }^{9,10}$. Although professional help and nicotine replacement therapies significantly increase quit rates, most smokers try to quit spontaneously ${ }^{11}$. As described in a widespread model, smoking cessation is a process through different motivation stages ${ }^{12,13}$. Motivation is a key element for success, as shown by higher cessation rates for self-referred smokers than for those referred by hospital services ${ }^{6,14}$.
In psychiatric hospitals, smoking cessation is not a primary issue for staff and patients, who are mainly "precontemplators" according to the Stage of Change Model ${ }^{12,15,16}$. They require intensive mental health care and frequently suffer from motivational deficiencies associated with psychopathology. Thus, reinforcing motivation and providing an opportunity to think about cigarette consumption might be a prerequisite in tobacco-related interventions intended for psychiatric inpatients. The present study reports on the feasibility of a brief 25-hour motivational intervention in Geneva.

\section{Methods}

\section{Program description}

The program is based on a group experience and the challenge of not smoking during one day and the following night. During the 25-hour abstinence period, strong incentives are given to patients, through positive experiences associated with non-smoking. Proposed activities imply a major change from the usual hospital environment: thermal baths, lunch in an outdoor restaurant, interactive session with a smoking cessation specialist, afternoon tea and music therapy. Group sessions and informal discussions 
about the ongoing experience take place during the whole day ( 8 h $30-18$ h). Patients return to the hospital at night and a final group session is held in the next morning. Participants who successfully refrain from smoking obtain a personal certificate.

Nicotine replacement is offered free of charge during the abstinence period as well as during hospitalization (1-mg nicotine lozenges, 2- and 4-mg nicotine gums, 10-mg nicotine inhalers and 21-mg nicotine patches). Participation implies no extra charge for patients.

\section{Participants}

The intervention was proposed on 3 occasions to all smokers admitted at the public psychiatric hospital of Geneva, Switzerland, where a total smoking ban is applied indoors but patients can smoke outside the buildings. Nineteen patients participated in these 3 interventions.

\section{Measures}

Before the intervention, baseline smoking rate (average number of cigarettes per day (CPD) in the past week) and smoking history were collected, together with Heaviness of Smoking Index (HSI) ${ }^{17}$, stage of motivation to quit ${ }^{13}$ and self-efficacy about smoking cessation ("I am sure that one day, whatever happens, I'll stop smoking"; 1 = "never, it's impossible" to 5 = "yes, absolutely").

Self-reported smoking abstinence during the day (10-hours) and next night (25-hours) were recorded. Level of exhaled breath carbon monoxide was measured on 3 occasions (intervention day $9 \mathrm{~h} 00$ and $17 \mathrm{~h} \mathrm{30, \text {next }}$ day $9 \mathrm{~h} \mathrm{00).}$
At the end of the intervention (next day 9 h 30) use of nicotine replacement, general well-being ( 1 = “I'm feeling much less well than the previous days" to $8=$ "I'm feeling much better than the previous days") and global satisfaction ( $1=$ "not satisfied at all" to $8=$ "extremely satisfied") were reported. For the last 2 interventions, seven withdrawal symptoms (Table 2) were recorded (1 = "much less than usual" to $5=$ "much more than usual").

One week after the intervention HSI, stage of motivation and self-efficacy were reassessed. Self-reported CPD was retrospectively recorded for each day between intervention and assessment.

\section{Results}

\section{Sample description}

Table 1 presents the baseline characteristics of participants who are mostly heavy smokers (median CPD $=20 ; 68.4 \%$ smoking $\geq 20 \mathrm{CPD}$; median HSI = 4) and in a "precontemplation" stage (52.6\%).

\section{Smoking abstinence}

Smoking abstinence was successful for $78.9 \%$ of participants during the 10-hour period, and $47.4 \%$ in the 25 -hour period (Table 2).

Sixteen patients used one or several types of nicotine replacement [lozenges $(n=11)$, inhalers $(n=10)$, patches $(n=7)$, chewing gums $(n=6)]$. Carbon monoxide level decreased significantly (median $24 \mathrm{ppm}$ at $9 \mathrm{~h}$, $9 \mathrm{ppm}$ at $17 \mathrm{~h} 30,9 \mathrm{ppm}$ at $9 \mathrm{~h}$ the next day; Friedman ANOVA, df = 2, $\mathrm{p}=0.0001$ ). 
Table 1

Participant characteristics $(\mathrm{n}=19)$

\begin{tabular}{|c|c|c|c|c|}
\hline Characteristic & $\mathrm{n}$ & $\%$ & median & range \\
\hline \multicolumn{5}{|l|}{ Gender } \\
\hline female & 5 & 26.3 & & \\
\hline male & 14 & 73.7 & & \\
\hline \multicolumn{5}{|l|}{ Age } \\
\hline$<25$ & 7 & 36.8 & & \\
\hline$\geq 25$ & 12 & 63.2 & & \\
\hline \multicolumn{5}{|l|}{ Diagnosis } \\
\hline psychotic or schizophrenic disorder & 13 & 68.4 & & \\
\hline depressive disorder & 3 & 15.8 & & \\
\hline bipolar disorder & 2 & 10.5 & & \\
\hline other & 1 & 5.3 & & \\
\hline Number of psychiatric hospitalizations & & & 3 & $1-60$ \\
\hline Years since onset of smoking & & & 12 & $1-39$ \\
\hline Number of cigarettes per day & & & 20 & $5-50$ \\
\hline
\end{tabular}

Number of cigarettes per day

$\begin{array}{lrr}\geq 20 & 13 & 68.4 \\ 10 \quad 19 & 3 & 15.8 \\ <10 & 3 & 15.8\end{array}$

\begin{tabular}{llll}
\hline HSI score & 4 & $0-7$ \\
\hline
\end{tabular}

Stage of change

precontemplation $\quad 10 \quad 52.6$

$\begin{array}{lll}\text { contemplation } & 9 & 47.4\end{array}$

preparation $\quad 0 \quad 0$

Attempt to stop smoking in the past 6 months

$\begin{array}{lrr}\text { yes } & 5 & 26.3\end{array}$

$\begin{array}{lll}\text { no } & 14 & 73.7\end{array}$

General well-being, withdrawal symptoms and global satisfaction

Perceived general well-being during the abstinence day was high (median $=6$ ). Frequency of withdrawal symptoms was low, with $\leq 3$ patients rating symptoms as "much more than usual" or "more than usual". On the contrary, 4 to 6 patients perceived benefits of smoking abstinence with respect to sleep disturbance, anxiety or inner tension, craving for cigarettes, depressive mood and concentration difficulties. Patients expressed a high satisfaction about the intervention $($ median $=7)($ Table 2$)$. 
Table 2

Temporary smoking abstinence rates, general well-being, satisfaction and withdrawal symptoms during the intervention $(\mathrm{n}=19)$

\begin{tabular}{|c|c|c|c|c|c|}
\hline Characteristic & & $\mathrm{n}$ & $\%$ & median & range \\
\hline Temporary smoking abstinence & $<10$ hours & 4 & 21.1 & & \\
\hline & 10 hours & 6 & 31.6 & & \\
\hline & 25 hours & 9 & 47.4 & & \\
\hline General well-being & & & & 6 & $2-8$ \\
\hline Satisfaction & & & & 7 & $5-8$ \\
\hline Withdrawal symptoms* & & & & & \\
\hline sleep disturbances & (much) less than usual & 5 & 45.5 & & \\
\hline & as usual & 5 & 45.5 & & \\
\hline & (much) more than usual & 1 & 9.1 & & \\
\hline anxiety or inner tension & (much) less than usual & 4 & 36.4 & & \\
\hline & as usual & 5 & 45.5 & & \\
\hline & (much) more than usual & 2 & 18.2 & & \\
\hline craving for cigarettes & (much) less than usual & 5 & 45.5 & & \\
\hline & as usual & 4 & 36.4 & & \\
\hline & (much) more than usual & 2 & 18.2 & & \\
\hline depressive mood & (much) less than usual & 4 & 36.4 & & \\
\hline & as usual & 6 & 54.5 & & \\
\hline & (much) more than usual & 1 & 9.1 & & \\
\hline irritability or aggressiveness & (much) less than usual & 3 & 27.3 & & \\
\hline & as usual & 6 & 54.5 & & \\
\hline & (much) more than usual & 2 & 18.2 & & \\
\hline dizziness, hot flushes or shivering & (much) less than usual & 1 & 9.1 & & \\
\hline & as usual & 7 & 63.6 & & \\
\hline & (much) more than usual & 3 & 27.3 & & \\
\hline concentration difficulties & (much) less than usual & 6 & 54.5 & & \\
\hline & as usual & 3 & 27.3 & & \\
\hline & (much) more than usual & 2 & 18.2 & & \\
\hline
\end{tabular}

* symptoms recorded on the second and third interventions only $(\mathrm{n}=11,1$ missing value).

\section{Change between pre- and post-assessments}

Comparisons of pre- and 1-week post-intervention measures were performed on 15 subjects (4 persons had been discharged). Motivation stage remained stable for 12 patients. 3 patients changed their stage from "contemplation" to "action" (1), "precontemplation" to "contemplation" (1) and "contemplation" to "precontemplation" (1). After the intervention, 3 patients ("contemplators" at baseline) had decided to quit smoking: two succeeded for 3 days but relapsed thereafter and one was still abstinent after one week (“action"). 
Self-efficacy about smoking cessation showed no significant change (median 4 at pre- and post-intervention; Wilcoxon signed-rank test, $\mathrm{p}=0.5$ ).

CPD decreased over the days following the intervention (Figure 1). Reduced con- sumption persisted for at least one week, with a significant difference between the week before and 1-week after the intervention (median 20 vs. 15; Wilcoxon signedrank test, $\mathrm{p}=0.003$ ).

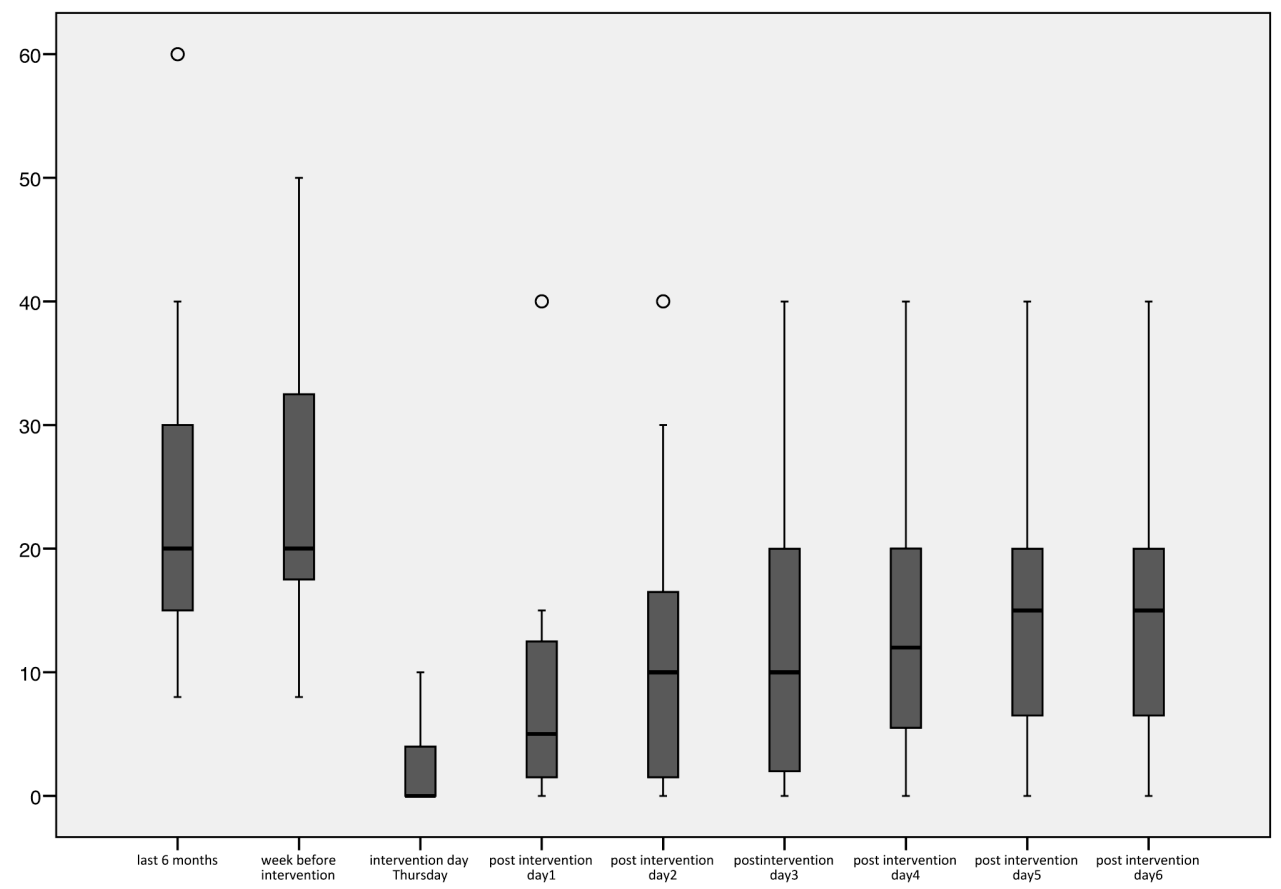

Figure 1. Number of cigarettes per day as a function of time $(n=15)$.

\section{Discussion}

Recent American Psychiatric Association (APA) guidelines about treatment of nicotine dependence recommend treating every tobacco user seen in a health care setting and offering motivational approaches for those not ready to attempt cessation ${ }^{18}$. However little is known about which smoking cessation programs are effective for psychiatric inpatients.
The described new intervention relies on the association of positive experiences with temporary abstinence, using reinforcement strategies to enhance motivation and reflection about smoking. Temporary smoking cessation, instead of reduction, was chosen because even a short abstinence period has physical consequences (e.g. improved breath and cardiovascular parameters) that patients might experience immediately ${ }^{19}$. Engaging in this challenge is a powerful motivator. 
Effects of such a brief intervention on internal processes about smoking are difficult to measure. We observed no significant change with respect to stage of motivation to quit. However, two patients actually expressed a demand for a subsequent follow-up and another stopped smoking. Several others said the intervention allowed them to realize that it was possible to abstain from smoking. Furthermore, decreased tobacco consumption for at least 1 week indicated that the 1-day intervention was able to trigger some observable change in smoking behaviors, at least in the short-term.

In a sample including a majority of heavy smokers, only a few patients reported withdrawal symptoms, whereas several reported some temporary relief when compared with baseline. No deterioration of psychiatric condition was observed, in agreement with earlier work ${ }^{20}$. Clinical condition may even benefit from treatment of tobacco dependence ${ }^{20}$ and some approaches, such as Behavioral Activation, simultaneously target smoking and depressive symptoms ${ }^{21-23}$.

Our feasibility study has methodological limitations, in particular its uncontrolled open design, use of non-validated instruments, short 1-week observation period, small sample size and sample characteristics limiting generalization of conclusions.

We showed that the proposed brief motivational intervention is feasible, acceptable and promising in a psychiatric hospital. Integrative approaches to nicotine addiction and psychiatric disorders deserve further development and validation in patients for whom usual cessation programs often remain out-of-view or out-of-reach.

\section{References}

1. Lasser K, Boyd JW, Woolhandler S, Himmelstein DU, McCormick D, Bor DH. Smoking and mental illness: A population-based prevalence study. JAMA 2000; 284(20): 2606-2610.

2. Ziedonis D, Hitsman B, Beckham JC, Zvolensky M, Adler LE, Audrain-McGovern J, et al. Tobacco use and cessation in psychiatric disorders: National Institute of Mental Health report. Nicotine Tob Res 2008; 10(12): 1691-1715.

3. Lawn S, Pols R. Smoking bans in psychiatric inpatient settings? A review of the research. Aust N Z J Psychiatry $2005 ; 39(10): 866-885$.

4. Green MA, Hawranik PG. Smoke-free policies in the psychiatric population on the ward and beyond: A discussion paper. Int J Nurs Stud 2007; 45: 1543-1549.

5. Kisely S, Campbell LA. Use of smoking cessation therapies in individuals with psychiatric illness: an update for prescribers. CNS Drugs 2008; 22(4): 263-273.

6. Ranney L, Melvin C, Lux L, McClain E, Lohr KN. Systematic review: smoking cessation intervention strategies for adults and adults in special populations. Ann Intern Med 2006; 145(11): 845-856.

7. McChargue DE, Gulliver SB, Hitsman B. Would smokers with schizophrenia benefit from a more flexible approach to smoking treatment? Addiction 2002; 97(7): 785-793; discussion 795-800.

8. Hatsukami DK, Stead LF, Gupta PC. Tobacco addiction. Lancet 2008; 371(9629): 2027-2038.

9. Ferguson J, Bauld L, Chesterman J, Judge K. The English smoking treatment services: one-year outcomes. Addiction 2005; 100 (Suppl 2): 59-69.

10. Fiore MC. Treating tobacco use and dependence: an introduction to the US Public Health Service Clinical Practice Guideline. Respir Care 2000; 45(10): 1196-1199.

11. Fiore MC, Novotny TE, Pierce JP, Giovino GA, Hatziandreu EJ, Newcomb PA, et al. Methods used to quit smoking in the United States. Do cessation programs help? JAMA 1990; 263(20): 2760-2765.

12. DiClemente CC, Prochaska JO, Fairhurst SK, Velicer WF, Velasquez MM, Rossi JS. The process of smoking cessation: an analysis of precontemplation, contemplation, and preparation stages of change. J Consult Clin Psychol 1991; 59(2): 295-304.

13. Woody D, DeCristofaro C, Carlton BG. Smoking cessation readiness: are your patients ready to quit? J Am Acad Nurse Pract 2008; 20(8): 407-414. 
14. Baha MY, Le Faou AL. Smoking cessation interventions offered to French adult light smokers: a heterogeneous population with specific needs. Eur Addict Res 2010; 16(3): 162-169.

15. Solty H, Crockford D, White WD, Currie S. Cigarette smoking, nicotine dependence, and motivation for smoking cessation in psychiatric inpatients. Can J Psychiatry 2009; 54(1): 36-45.

16. Keizer I, Descloux V, Eytan A. Variations in smoking after admission to psychiatric inpatient units and impact of a partial smoking ban on smoking and on smoking-related perceptions. Int J Soc Psychiatry 2009; 55(2): 109-123.

17. Etter JF, Vu Duc T, Perneger TV. Validity of the Fagerström test for nicotine dependence and of the Heaviness of Smoking Index among relatively light smokers. Addiction 1999; 94(2): 269-281.

18. APA. Clinical Practice Guidelines and Other Professional Resources. American Psychiatric Association; Accessed on October 11th 2010; Available from:
http://www.psych.org/MainMenu/PsychiatricPractice/AddictionPsychiatry/ClinicalPracticeGuidelinesandOther.aspx.

19. Anderson ME, Belani KG. Short-term preoperative smoking abstinence. Am Fam Physician 1990; 41(4): 1191-1194.

20. Hitsman B, Moss TG, Montoya ID, George TP. Treatment of tobacco dependence in mental health and addictive disorders. Can J Psychiatry 2009; 54(6): 368-378.

Author for correspondence:

Ineke Keizer

Division of General Psychiatry

2 chemin du Petit-Bel-Air, 1225

Chêne-Bourg

Phone: +00 41223054762

Fax: 0041223055799

E-mail: ineke.keizer@hcuge.ch 